The Geneva Papers on Risk and Insurance, 20 (No. 76, July 1995) 315-324

\title{
Risk Management: the State of the Art in Italy*
}

\author{
by Paola Tagliavini**
}

\section{The aims of the Survey}

The purpose of this paper is to provide a brief illustration of some of the most significant results to emerge from a research project entitled "The General Survey of Risk Management in Italy", carried out at the SPACE (Security and Protection against Crime and Emergencies) research centre of the Bocconi University. The aim of this research was to investigate the state of Risk Management in Italy. The management of pure risks in Italian companies is still underdeveloped and underestimated. Despite this, however, recent years have witnessed some encouraging signs and the conviction is spreading, both among academics and specialists in the sector, that phenomena favourable to a wider adoption of Risk Management are now beginning to emerge in Italy too.

The first goal of "The General Survey of Risk Management in Italy" was to ascertain the correctness of the idea that the state of the art was lagging behind - a proposition, moreover, that admitted of little doubt - while the second objective was to create a more accurate picture by trying to identify the diverse aspects of the problem and then subjecting them to individual examination. The Survey attempted to determine the extent to which businesses operating in Italy practice Risk Management and, where this was so, in what form. Where it was absent or only partly present, the Survey attempted to identify those areas in which the companies analysed were found to be stronger or weaker with a view to understanding if the diffusion of Risk Management in Italy will or will not become a concrete possibility in the immediate future.

This paper therefore comprises an outline of the essential characteristics of the research, a review of some of the most significant data to emerge from the Survey, and a brief elaboration of the data aimed at presenting some of the principal conclusions regarding the state of Risk Management in Italy.

* The author wishes to thank Nicola Misani for his invaluable assistance in elaborating the paper, and acknowledges editorial assistance and useful comments by Professors Gerard COLSON (University of Liege) and Antonio Borghesi (University of Verona). This paper was presented at the "Fourth Mini Euro Conference" devoted to Risk Management, held in Licge on May 1994. This conference, chaired by Professor Colson, was jointly organized by EURO (thc European Fedcration of Operation Research Societies) and AEAI (l'Association européenne des assurés de l'industrie).

** Researcher with SPACE (Sccurity and Protcetion against Crime and Emergencics), the European Research Ccnter of the Bocconi University, Milan, Italy. 
As far as characteristics of the Survey are concerned,we decided to observe the behaviour of a very wide range of companies operating in Italy, comprising 1,649 names taken from the Annual Mediobanca Report on the most important Italian companies and from the list of ANRA members (an acronym for the National Association of Risk Managers and Insurers). This sample group includes all Italian companies with a turnover of more than 20-25 billion lire and covers all industrial and service sectors including banks but excluding insurance companies.

The companies were contacted by means of a questionnaire, sent by post, made up of 56 questions regarding the principal arguments connected with the management of pure risks. The number of completed questionnaires received within the time limit was 181 , of which 179 were usable. The response rate was $11 \%$ which is a positive result if we consider the mean response rate for research of this type and the complexity of the questionnaire.

The results were slightly distorted by the fact that the respondents were the most interested, best informed, and best organized companies. This distortion is nonetheless acceptable inasmuch as the goal of our research was to investigate innovational trends where such phenomena were beginning to emerge.

\section{A résumé of the data}

Before moving on to an analysis of the principal data to emerge from the Survey, it should first be pointed out that the questionnaire included three different definitions of Risk Management:

- the first, described as "overall management of risk", and comparable therefore to Risk Management proper, corresponded to the unified management, subject to a single authority or a single co-ordinator, of the three fundamental instruments of Risk Management: in the questionnaire the formulation used referred to "overall risk policy, with responsibilities extending from the management of insurance policies to the setting up of prevention plans and self-insurance";

- the second, described as "risk transfer", corresponded to what we might more properly term "Insurance Management", whereby the management of risk is identified with insurance transfer;

- the third, described as "the operative management of policies", which in practice consists of Insurance Management reduced to the essentials, refers to a concept whereby insurance, rather than an instrument for the management of risk, becomes a mere administrative problem.

The Survey asked respondents to choose which of these three definitions most resembled their duties and responsibilities (figure 1). The results show that only a little more than $25 \%$ stated that they practiced Risk Management in the correct sense of the term. Moreover, we also have to ask ourselves if this figure, already indicative of underdevelopment, has not been inflated as a result of over optimistic assessments on the part of the respondents. We shall come back to this problem shortly.

It is also interesting to observe distribution in relation to dimensions (figure 2). From this point onwards we have divided the companies sampled into four dimensional categories: from 0 to 500 employees; from 501 to 1500 ; from 1501 to 5000 ; and over 5000 employees. 
Fig. 1: Responsibilities of the Risk Manager

Overall data

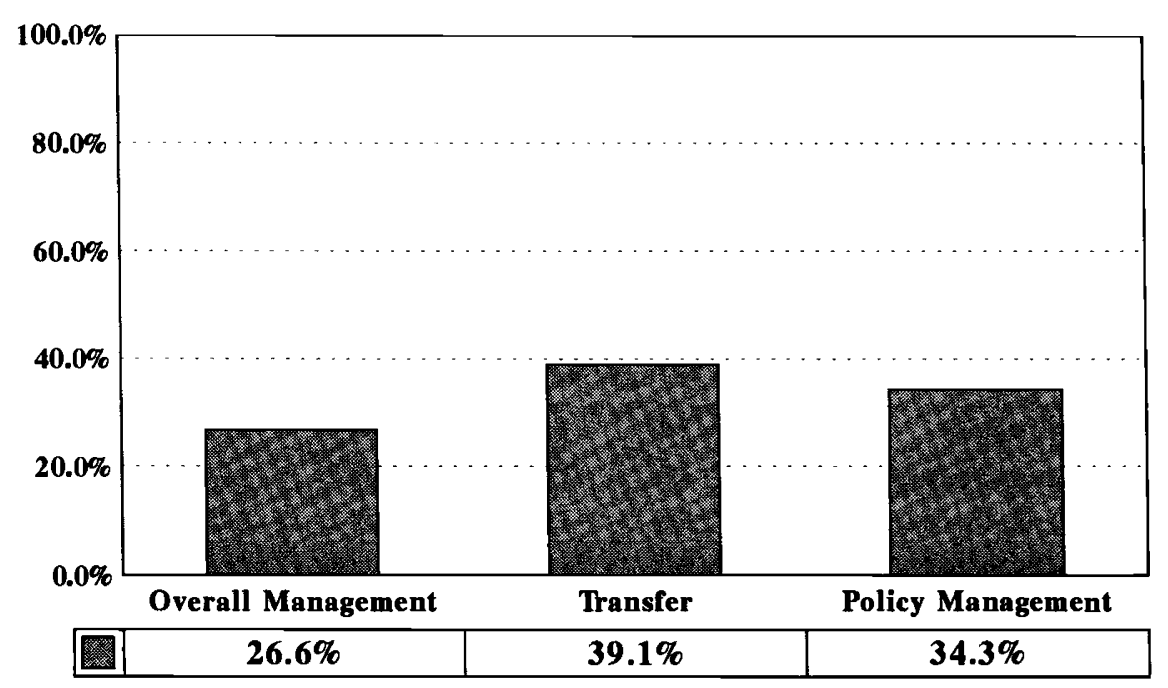

Fig. 2: Responsibilities of the Risk Manager

Dimensional category data

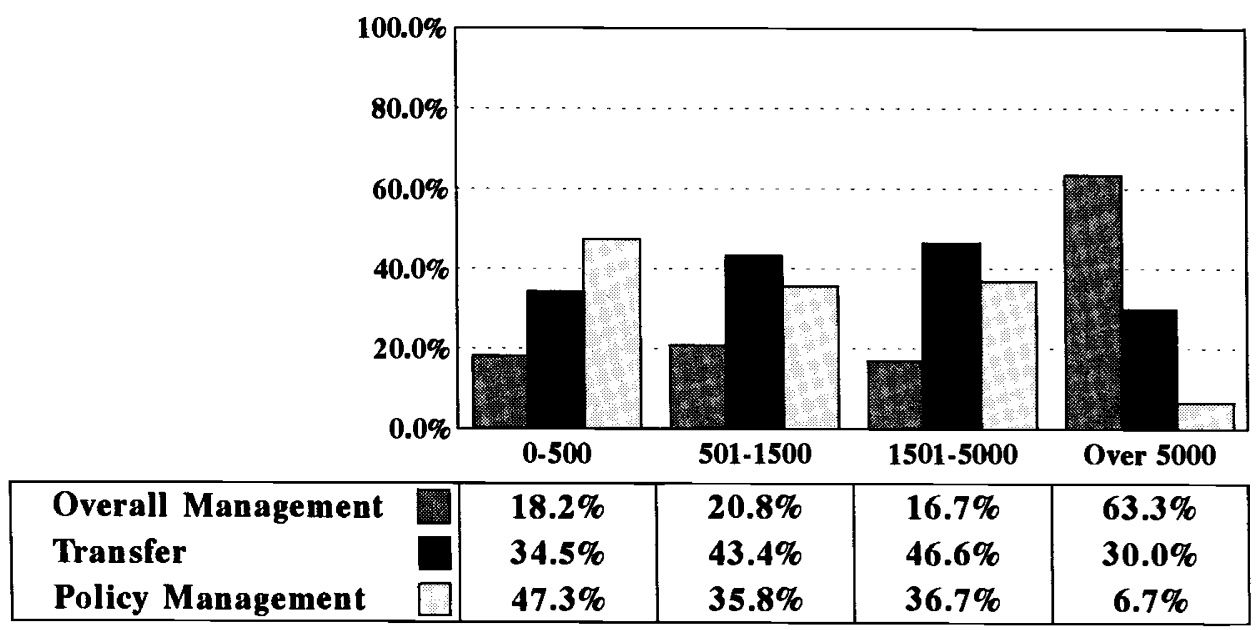

Categories (per number of employees) 
Fig. 3: Formal titles of those responsible for pure risks

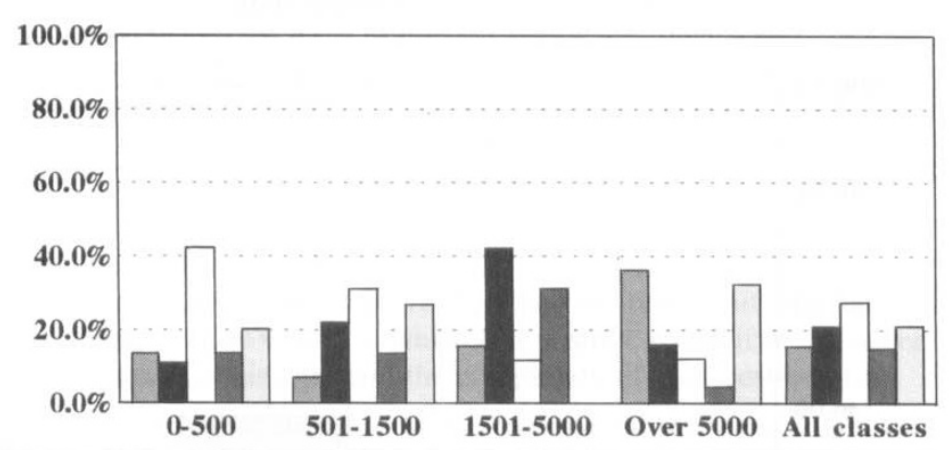

\begin{tabular}{|ll|c|c|c|c|c|}
\hline Risk Manager & $\square$ & $13.3 \%$ & $6.7 \%$ & $15.4 \%$ & $36.0 \%$ & $15.5 \%$ \\
Insurance Manager & & $11.1 \%$ & $22.2 \%$ & $42.3 \%$ & $16.0 \%$ & $21.1 \%$ \\
Admin. \& Finance & $\square$ & $42.2 \%$ & $31.1 \%$ & $11.5 \%$ & $12.0 \%$ & $27.5 \%$ \\
General services & & $13.3 \%$ & $13.3 \%$ & $30.8 \%$ & $4.0 \%$ & $14.8 \%$ \\
Other & $\square$ & $20.1 \%$ & $26.7 \%$ & $0.0 \%$ & $32.0 \%$ & $21.1 \%$ \\
\hline
\end{tabular}

Categories (per number of employees)

Fig. 4: The presence of a Risk Management department

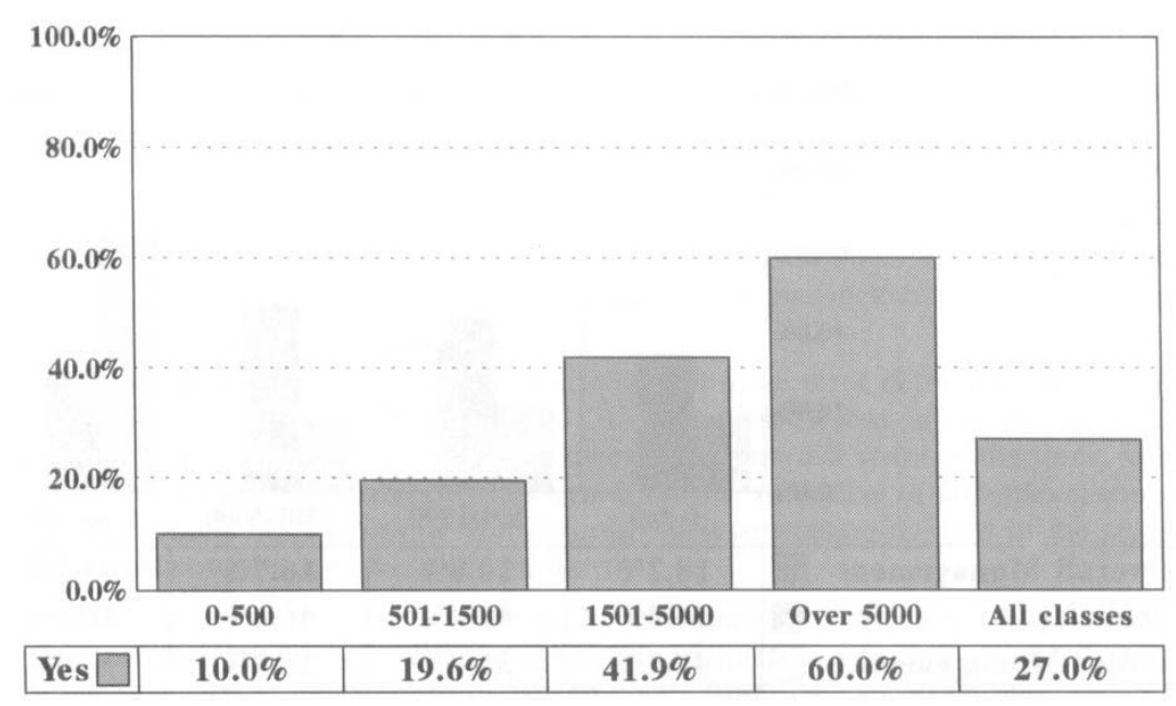

Categories (per number of employees) 
In the first two categories, overall management was found to be $20 \%$, a figure that touched $60 \%$ in the fourth class. This would seem to confirm the widespread idea that the size of an organization has a marked influence on company policy when it comes to pure risks despite the fact that, when we move from the second to the third class, we note both a reduction in the percentage of businesses stating that they operate an overall Risk Management policy and an increase in the percentage of those that confine themselves to operative policy management.

The formal title of those dealing with the management of pure risks is subject to some variation (figure 3). While in some cases the position was described as Risk Manager or Insurance Manager, in others the title indicated by the respondents referred to wider responsibilities. This second circumstance should be considered as being indicative of an absence of resources specifically allotted to Risk Management.

A distinct divergence emerges from the data. The first group is charactcrized by nonspecialist personnel, most of which usually work in the administrative and financial divisions; in the successive classes we arc in the presence of a shift, first towards the Insurance Manager, then towards the Risk Manager. But great caution must be adopted with regard to titles such as Risk Manager and Insurance Manager, which do not necessarily correspond to the duties normally assigned to them in theory. A safer comparison is offered by figure 4 showing the percentage of companies that stated that they possessed a function, a department, or a combination of staff and resources devoted to Risk Management. The overall percentage was very low, however, and it is interesting to note that the percentage of positive responses was very close to the percentage of respondents operating an overall risk policy, while there was a marked positive relationship with the size of the company.

The Survey went on to examine a series of aspects linked to risk analysis, the relationships between businesses and insurance companies, and risk retention. It might prove useful to attempt to provide a brief overview of the situation in Italy by bringing together the mass of data collected, from which we have identified some trends that can be extrapolated from the divergent responses to the individual questions.

The fact that the respondents stated that they had set up an overall Risk Management policy is obviously not enough to persuade us that Risk Management in the fullest sense of the term has been introduced in a company. The questions posed in the Survey focussed on most of the principal concepts linked to the management of risks and allowed us to construct a clearer picturc of the state of the art in Italy. Once the job of analysing and intcrpreting the data had been completed, wc wcre spontaneously moved to define precisely and concisely the percentage of those companies sampled in which Risk Management could be said to have reached satisfactory levels.

With this in mind, the following remarks represent an attempt to quantify the diffusion of Risk Management based on an analysis of the answers to the questions posed by the Survey. We identified eight variables, which seem particularly indicative of the implementation of Risk Management principles in accordance with the concept of overall management as outlined earlier. Each variable was submitted to a test with the level of the variable being considered "fair" once it had passcd scvcral other tests. The variables in question are:

a) formal internal recognition: that is to say, the measure of the degree to which the organization, top management in particular, belicves Risk Management to be a subject worthy of interest, at least on a formal level; 
b) the quality of the relationship with the insurers is the measure of the professionalism and competence with which businesses tackle the problem of insurance cover;

c) general instruction is the measure of professional training posscssed by those concerned with pure risk;

d) autonomy is the measure of independent action and the freedom to choose the means best suited to the attainment of the assigned objectives;

e) the integration of insurance and prevention is the measure of the extent to which the oftquoted overall management of risk has actually been implemented;

f) risk analysis is the measure of the availability of sufficient information to provide for an adequate decision-making procedure;

g) the financial management of risk is the measure of the systematic use of retention and the financial instruments of Risk Management as alternatives to insurance and prevention;

h) the use of quantitative methods is the measure of recourse to decision-making methods in keeping with criteria based on quantity and profitability.

The results of this analysis are illustrated in figure 5, which shows the percentages of "fair results" scored by the companies sampled for each of the variables listed here. These data may be interpreted as an indication of the strengths and weaknesses of Italian Risk Management. Note in particular that:

- a positive situation emerges, at least on paper, regarding the more generic aspects (recognition, general instruction, autonomy) as well as the quality of the relationship with the insurers;

Fig. 5: The overall state of Risk Management Overall data

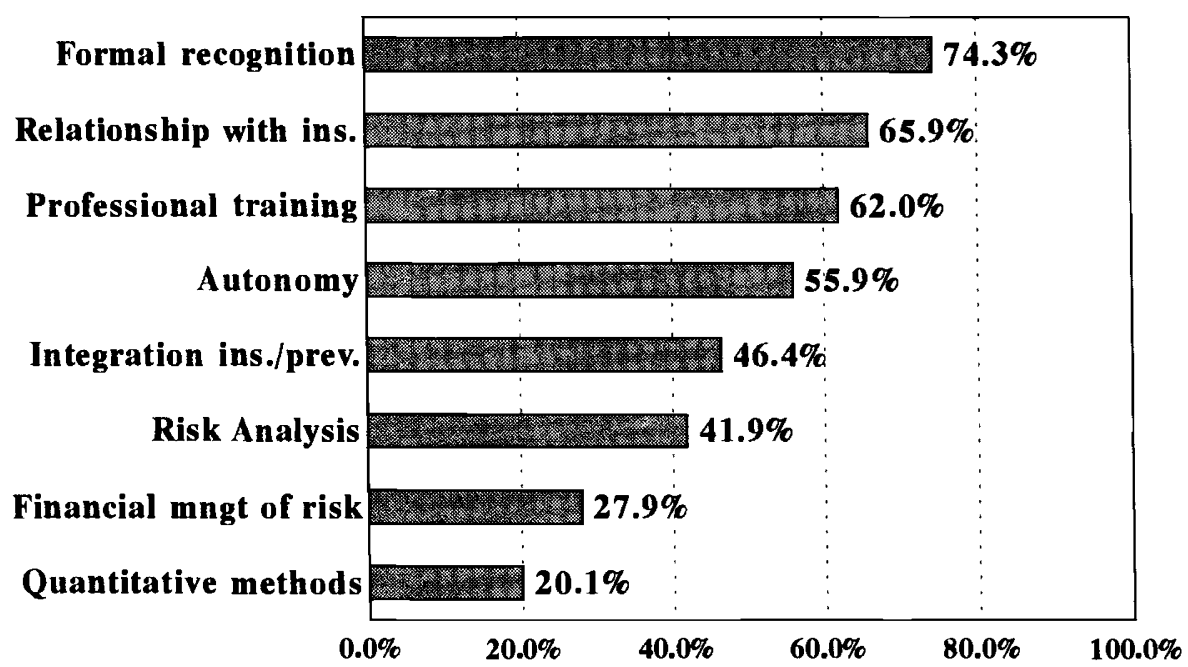


- the lowest positions (with a percentage of "fair results" amounting to less than $50 \%$ ) were occupied by all attributes most typical of Risk Management (integration of insurance and prevention, risk analysis, the financial management of risk, and the use of quantitative methods);

- the presence of risk analysis and quantitative methods became much more marked in relation to the size of the company.

The analysis of the data also enabled us to highlight, in decreasing order, five different types of Risk Management (figure 6).

The letter A stands for those respondents (only two in the entire sample) that scored eight "fair results" and can thus - within the limits of the procedure adopted for the Survey - be described as fully-fledged Risk Managers. The letter B instead corresponds to seven "fair results" and therefore designates what we might describe as "incomplete" Risk Management. The letters C (five or six "fair results") and D (three or four "fair results") refer to situations in which Risk Management has yet to be implemented, even though the first signs of positive development are present. The letter E (from nil to two "fair results") shows that the management of pure risks is still carried out using antiquated and inadequate methods.

The data shown in the table are beyond doubt and make it clear that Risk Management is still limited to a rather restricted group (little more than eight percent if we add A and B together) even though the percentage is exactly one third in the fourth dimensional category. On the other hand, Risk Management appears to be completely unknown to companies with less than 500 employees. The outright majority of the companies making up these categories is concentrated in classes $\mathrm{C}$ and $\mathrm{D}$. It is also noteworthy that, in accordance with

Fig. 6: Types of Risk Management in Italy

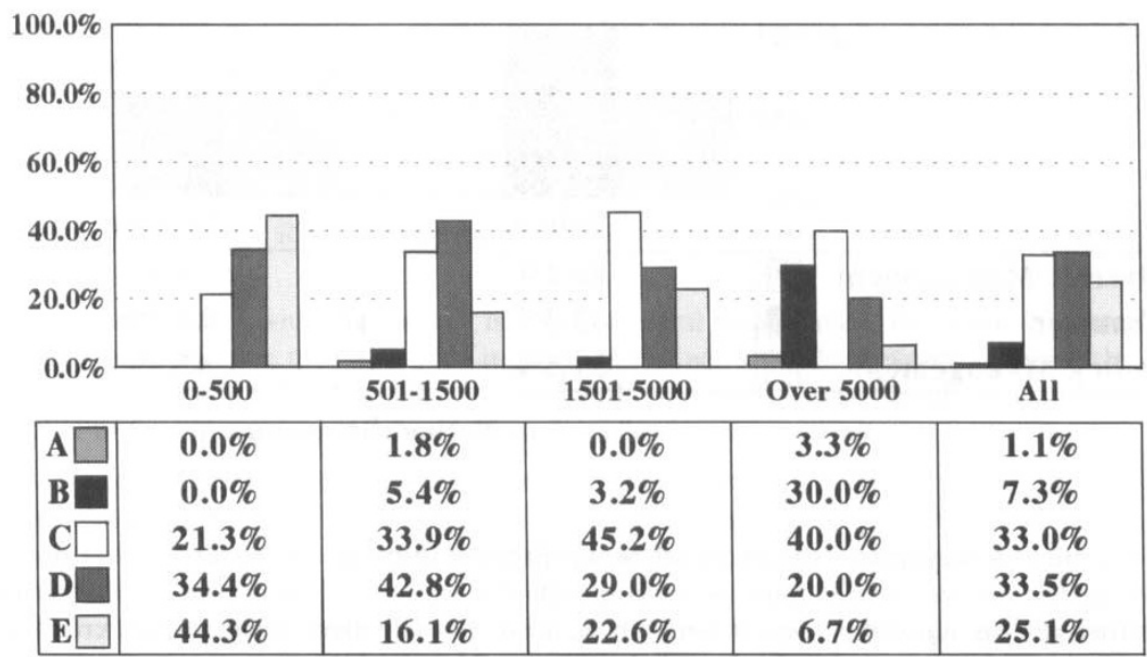

Categories (per number of employees) 
other data found in the Survey, the third class performed slightly worse than the second (with this in mind, note the datas for classes A, B and E). This seems almost like a warning not to attempt an organizational emancipation of the management of pure risks unless all the necessary conditions have reached maturity.

It is also interesting to break up the results according to the nationality, Italian or foreign, of the companies. One might well expect to find - since Risk Management is more widespread abroad - that foreign-based parent companies with branches operating in Italy would perform better thanks to the transfer of more highly developed management models. In reality the situation is more complex.

The statements reveal that, as far as overall Risk Management is concerned, the profiles of the two groups are substantially similar, while we can see clear growth in terms of the operative management of policies (figure 7). This has to be explained by the decision on the part of many multinational groups to keep Risk Management programmes strictly centralized within the parent company, leaving individual local units to deal solely with the administrative aspects of the management of policies and claims.

\section{Fig. 7: Responsibilities of the Risk Manager}

Nationality data

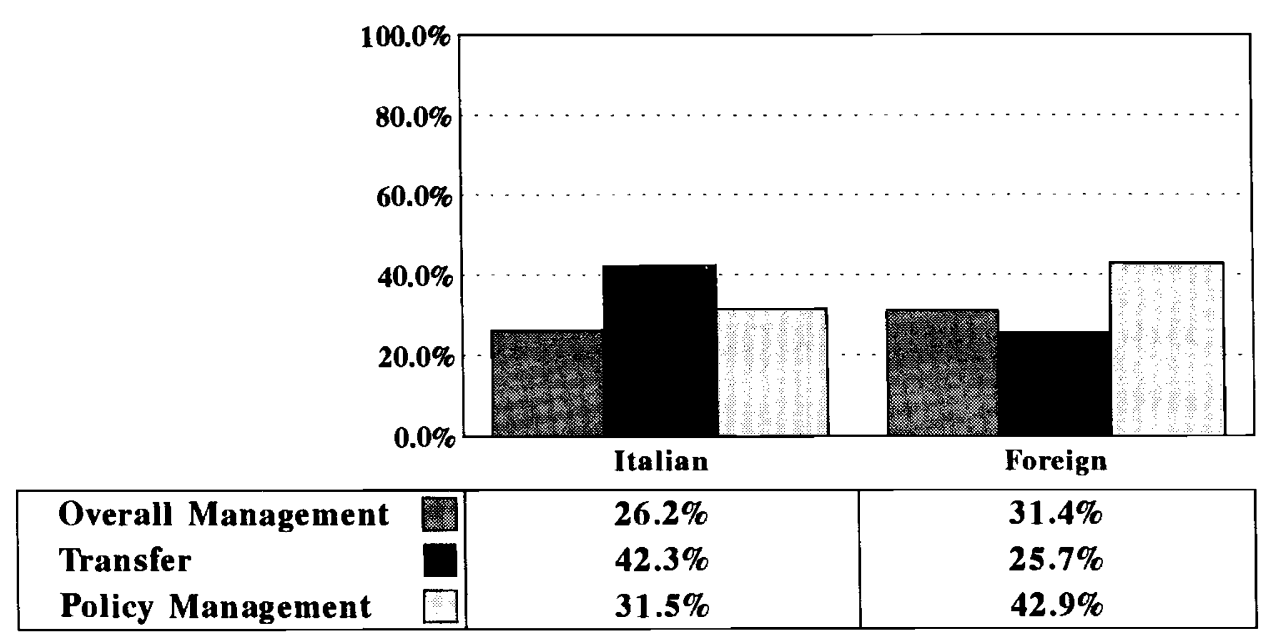

Nationality groups

It comes as no surprise therefore when we discover that the overall situation, obtained following the analysis of the data, is substantially the same for Italian and foreign firms even though this naturally regards only those Risk Management programmes created in Italy - because foreign companies benefit in any case from Risk Management schemes organized within the parent company (figure 8). 
Fig. 8: Types of Risk Management in Italy

Nationality data

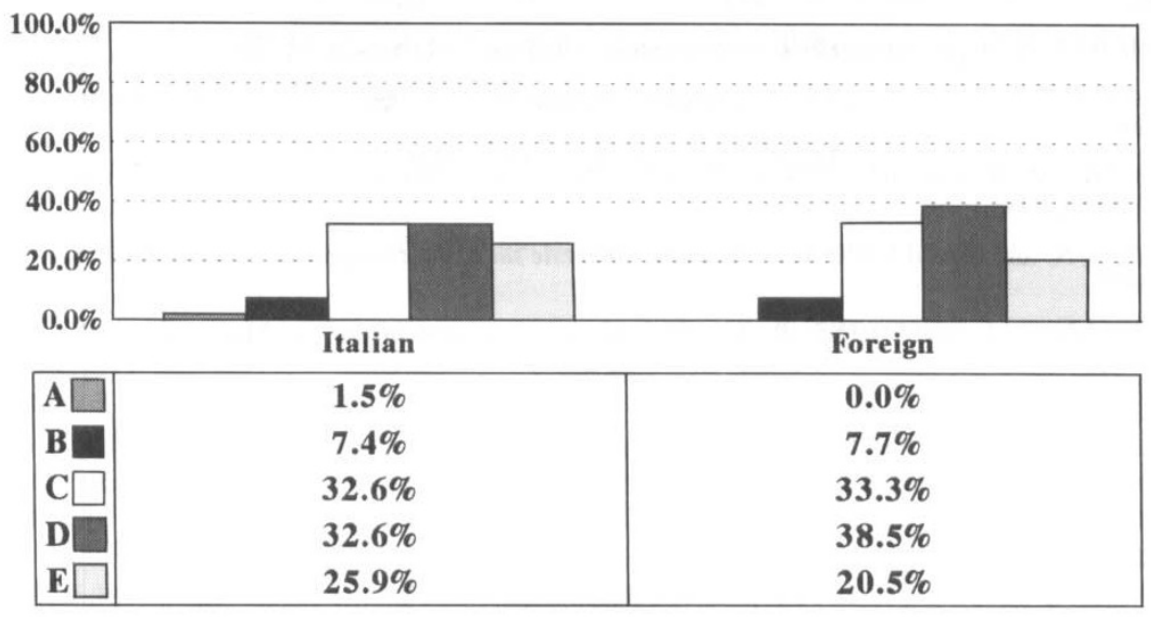

Nationality groups

In conclusion we can sum up the results of the Survey with the following observations:

a) as far as Risk Management is concerned, the Survey shows that Italy is lagging behind to an alarming extent;

b) this "development lag" is not only relevant to certain specific problem areas, but affects all aspects of Risk Management in general;

c) the bigger companies stand out clearly from medium- and small-sized concerns, but even in their case Risk Management cannot be said to have reached a satisfactory stage of development;

d) the relationship with the insurer is still of central importance, but while it is true that insurance practice provides little incentive to move towards prevention, given the incapacity to link the level of the premium with effective damage levels, it is equally true that not many companies showed much inclination to improve;

e) we cannot expect foreign firms to act as locomotives capable of pulling Italian businesses along behind them, inasmuch as foreign firms mostly operate centralized models of Risk Management policy created in-house by the parent company.

Nevertheless, we noted some encouraging signs while occasions such as this one, where the academic, insurance and industrial worlds can get together, may serve to boost the development of Risk Management in Italian business too. 


\section{REFERENCES}

BAGLINI, N. A., Risk Management in American Multinational and International Corporations, Risk Studies Foundation, New York, 1976.

BORGHESI, A., La gestione dei rischi di azienda, CEDAM, Padova, 1985.

DOHERTY, N. A., Corporate Risk Management, McGraw Hill, New York, 1985.

GILARDONI, A., La Protezione Aziendale: impostazione strategica e gestionale, EGEA, Milano, 1992.

GREENE, M. R. and SERBEIN, O. N., Risk Management: Text and Cases, Reston Publishing Co., Reston, 1983.

MISANI, N. and TAGLIAVINI, P., Indagine Generale sul Risk Management in Italia, EGEA, Milano, 1995.

WILLIAMS C. A. and HEINS, R. M., Risk Management and Insurance, McGraw Hill, New York, 1989. 